\title{
OCORRÊNCIA DE Listeria monocytogenes EM REFRIGERADORES E PIAS DE COZINHAS DOMICILIARES NOS MUNICÍPIOS DE OURO, CAPINZAL E ZORTÉA, SC - BRASIL.
}

\author{
Roberto Degenhardt \\ degenhardt_sc@yahoo.com.br \\ Régis Paulo Fernandes de Almeida \\ regismister@yahoo.com.br
}

\begin{abstract}
RESUMO: Listeria monocytogenes é o agente causal da listeriose em humanos, apresentando uma taxa de mortalidade nos grupos de risco de $30 \%$. Os idosos, indivíduos imunocomprometidos, neonatos e fetos são os principais acometidos pela doença, que se caracteriza por um quadro de septicemia e aborto no caso de fetos. A capacidade de se multiplicar em condições desfavoráveis deve-se a sua autoplasticidade desencadeada pela exposição a condições extremas sucessivas (frio, calor e acidez). Devido ao índice de surtos de doenças de origem alimentar predominar em condições domésticas, a observação da ocorrência de L. monocytogenes nos ambientes domiciliares propícios a sua sobrevivência e multiplicação é de grande importância. Foram avaliados os refrigeradores e as pias das cozinhas de sessenta residências dos municípios de Capinzal, Ouro e Zortéa, SC, através da coleta de esfregaços de superfície. As amostras foram colhidas do compartimento de verduras, de carnes e da borracha de vedação, e nas pias as amostras foram tomadas do ralo de esgotamento. Os resultados demonstraram a presença de $L$. monocytogenes nas bacias de carnes dos refrigeradores de três residências com a ocorrência simultânea de L. ivanovii em um deles. Verificase, portanto o risco de contaminação cruzada por $L$. monocytogenes nas residências devido à possibilidade de resíduos caírem sobre os alimentos, geralmente já preparados, armazenados nas prateleiras inferiores destes eletrodomésticos.
\end{abstract}

Palavras-chave: Listeria monocytogenes. Contaminação doméstica. Listeria ivanovii. 


\section{INTRODUÇÃO}

Listeria monocytogenes é o agente causal da listeriose em humanos, ocorrendo geralmente em pacientes imunocomprometidos após a ingestão de alimentos contaminados, sendo o trato gastrointestinal o sítio primário da entrada no hospedeiro (JAY, 2005). Nas duas últimas décadas do século XX esta doença deixou de ter uma importância limitada, tornando-se uma grande preocupação para a indústria alimentícia e autoridades da saúde.

Este microorganismo tem sido considerado o patógeno mais importante veiculado por alimentos, devido à alta taxa de mortalidade que provoca em grupos de risco (THÉVENOT, 2005), que segundo Sofos e Yoon (2006) pode alcançar a faixa de $20 \%$ a $30 \%$ dos casos diagnosticados, estimando-se que até $15 \%$ da população pertence ao grupo de alto risco, compreendendo mulheres grávidas e seus fetos, crianças, idosos e indivíduos imunocomprometidos.

É um microorganismo amplamente distribuído na natureza, sendo freqüentemente isolado a partir de materiais de vários ambientes, incluindo vegetação em decomposição, terra, ração animal, esgoto, água, plantas e o trato intestinal de homens e animais saudáveis (FORSYTHE, 2002).

Nos alimentos a L. monocytogenes chega através da matéria-prima contaminada, e pelo contato destas com o ambiente onde são manipuladas (EUZÉBY, 2000), portanto é praticamente impossível garantir a ausência destes microorganismos no ambiente de fabricação (BELL; KYRIAKIDES, 1998).

A resistência dos microorganismos deste gênero é variável, atingindo até dois anos no solo, e seis meses na silagem (EUZÉBY, 2000). Estudos têm demonstrado que a incidência de $L$. innocua e outras espécies não-patogênicas de Listeria é consideravelmente maior do que a incidência de L. monocytogenes (DUFFY et al., 2000). Esta condição pode ser devida à diferença das taxas de crescimento (DUFFY et al., 1994) e a produção de substâncias semelhantes a bacteriocinas produzidas por $L$. innocua (YOKOYAMA et al., 1998).

O processo de higienização é de grande importância na obtenção de alimentos seguros, pois este patógeno tem a capacidade de aderir às superfícies, interagindo com as mesmas, permitindo o início do crescimento celular e a formação de biofilmes (OLIVEIRA et al., 2006), aumentando a probabilidade de contaminação cruzada, e ambiental (JEONG; FRANK, 1994).

Em virtude da capacidade de se multiplicar em baixas temperaturas e a uma grande parcela dos surtos de doenças de origem alimentar ter origem nas refeições preparadas pelos consumidores em seus domicílios, a avaliação da ocorrência de L. monocytogenes nos ambientes propícios à sua sobrevivência e multiplicação nas residências torna-se bastante pertinente. Desta maneira a análise das superfícies de refrigeradores e cubas 
de pias se mostra um indicador interessante para avaliar a presença deste importante patógeno em condições domésticas.

\section{MATERIAL E MÉTODOS}

Foram coletadas amostras de superfícies de 60 refrigeradores e 60 pias de domicílios selecionados nos municípios de Ouro, Capinzal e Zortéa, SC - Brasil. As amostras foram obtidas através de esfregaço de superfície, empregando-se esponjas para coleta (Nasco, cód. B01245) de $3 \times 3 \mathrm{~cm}$, embebidas em Caldo D/E Neutralizing (Acumedia, cód.7562) para neutralização de compostos que poderiam inibir a multiplicação da Listeria durante a análise (resíduos de detergentes e sanitizantes). Os pontos coletados nos refrigeradores foram (1) a bacia de armazenamento de carne, logo abaixo do congelador, (2) a bacia de armazenamento de vegetais, última bacia, na base do refrigerador e (3) a borracha de vedação da porta do refrigerador. Também foi amostrada a cuba da pia (4), dando bastante foco à região de escoamento da água (4).

O protocolo de análise utilizado foi a ISO11290-1 (INTERNATIONAL STANDART ORGANIZATION, 2004), consistindo de um enriquecimento primário, onde sobre cada esponja foi adicionado $100 \mathrm{~mL}$ de Caldo Universidade de Vermont (UVM-Acumedia, cód. 7409A) e homogeneizado em Bag Mixer STOMACHER por dois minutos em velocidade normal, e incubada a $30^{\circ} \mathrm{C}$ por $24 / 48 \mathrm{~h}$ na ausência de luz.

A partir do enriquecimento primário, alíquotas de $0,1 \mathrm{~mL}$ do caldo de pré-enriquecimento foram repicadas para $10 \mathrm{~mL}$ de caldo de enriquecimento seletivo secundário, (Fraser Acumedia, cód. 7502A), e incubadas a 35ㄷ c por 24/48 horas. Havendo escurecimento do caldo (reação de esculinase), prosseguiu-se a análise. A não ocorrência de alteração da coloração do caldo indicou a ausência de Listeria spp na amostra.

As culturas presuntivamente positivas a partir do enriquecimento seletivo foram transferidas por estriamento para Agar Listeria Ottaviani Agosti (ALOA - Biolife, cód. 401605). As placas foram incubadas a $35^{\circ} \mathrm{C}$ por $24 / 48 \mathrm{~h}$, e as colônias típicas de Listeria spp, de coloração verde-azulada, sem halo (características do gênero), e as colônias de coloração verde-azulada com halo, (características de L. monocytogenes), foram transferidas para tubos de Agar Nutriente (AN - Acumedia, cód. 7145) para tipificação, através de kit miniaturizado API-Listeria (Biomerieux, cód. 223021) e prova de CAMP TEST em Agar Columbia suplementado com sangue de carneiro (CNA - Laborclin, cód. 900525).

\section{RESULTADOS E DISCUSSÃO}

Os dados levantados neste trabalho permitiram observar a presença de bactérias do gênero Listeria em 5,0\% dos refrigeradores amostrados, e não foi verificada a presença deste patógeno nas cubas das pias dos domicílios avaliados. Atribui-se a não detecção de Listeria nas pias divido a freqüência de higienização, empregando tanto agentes 
de limpeza como água quente, além da microbiota competidora apresentar maiores condições de sobrevivência.

Foram identificadas duas espécies do gênero, sendo L. monocytogenes a espécie mais abundante $(5,0 \%)$, e isolada nos três refrigeradores que apresentaram positividade. A outra espécie detectada foi $L$. ivanovii $(1,67 \%)$ em um dos mesmos refrigeradores que apresentaram contaminação pela outra espécie.

A presença de microorganismos do gênero Listeria já vem sido registrada em equipamentos de refrigeração há vários anos. Sergelidis et al. (1997) realizaram um extenso trabalho em de refrigeradores domésticos, comerciais (de varejo) e industriais, avaliando as superfícies de contato direto com alimentos, principalmente queijos e embutidos, além de produtos diversos. Nos aparelhos domésticos observaram a incidência de L. monocytogenes em $1,47 \%$ dos 136 avaliados. Em 228 refrigeradores comerciais verificaram a presença de Listeria sp em 3,1\% e 1,7\% de L. monocytogenes, e em uma amostragem de 22 câmaras de resfriamento industrial $4,5 \%$ de $L$. monocytogenes e $36,4 \% L$. innocua.

Azevedo (2005) observou a ocorrência de L. monocytogenes em três $(3,49 \%)$ amostras de um total de 86 refrigeradores em Portugal e ainda L. grayi $(4,65 \%)$ e L. innocua $(1,16 \%)$ nos mesmos equipamentos. Jackson et al. (2007) observaram a incidência de $1,2 \%$ de $L$. monocytogenes em superfícies de refrigeradores na Irlanda. Souza et al. (2008) comunicou o isolamento de $L$. monocytogenes em dois refrigeradores em um estudo brasileiro.

As três cepas de $L$. monocytogenes foram isoladas a partir de esfregaços das superfícies dos compartimentos de carnes, sendo este grupo de alimentos uma das prováveis fontes de contaminação, já que a contaminação de produtos cárneos, sobretudo os crus, é bastante conhecida (BALDASSI, 2005; MENDES, 2000; PELISSER, 1998). A cepa de $L$. ivanovii foi isolada do compartimento de vegetais, na porção inferior do eletrodoméstico.

O caráter ubiquitário deste gênero que os permite ser encontrado em uma grande diversidade de ambientes (GUERRA; BERNARDO, 2006), reforça a necessidade da higiene para com os alimentos antes destes serem armazenados nos refrigerados, já que os alimentos antes de chegarem aos domicílios são bastante manipulados permitindo a contaminação ao longo de toda cadeia produtiva. Mesmo uma embalagem, cuja função é a proteção do alimento, pode estar externamente contaminada e apresentar traços de matéria orgânica, suficientes para servirem de substrato à multiplicação dos microorganismos, e a partir dela contaminar as superfícies internas dos refrigeradores, onde encontram condições para o desenvolvimento de biofilmes (JEONG; FRANK, 1994; KESKININ; TODD; RYSER, 2008), e serem posteriormente transferidos para os alimentos, dos quais, os prontos para o consumo, que não exigem tratamento térmico antes da ingestão, são os mais susceptíveis a provocar uma infecções quando contaminados (JACKSON, et al., 2007). Deve-se ressaltar que sob condições de refrigeração a maioria dos microorganismos são inibidos diminuindo a pressão de competição permitindo o desenvolvimento de microorganismos psicrotróficos como Listeria. 


\section{CONCLUSÃO}

Os dados obtidos neste trabalham demonstraram a presença de L. monocytogenes nos refrigeradores domésticos das residências nas localidades estudadas se assemelham com os trabalhos já realizados sobre o mesmo tema.

A presença de L. monocytogenes, mesmo em um índice pequeno, reafirma a necessidade dos cuidados com a higiene dos alimentos ao nível doméstico, seja na limpeza dos eletrodomésticos e a manipulação e conservação dos gêneros alimentícios.

A observação de microorganismos patogênicos nas residências, onde poderiam ser facilmente controlados e eliminados, indica que a população deve ser melhor esclarecida quanto aos riscos aos quais está exposta, e iniciativas de pesquisa sobre a ocorrência de microorganismos patogênicos nas etapas seguintes à produção, como o ambiente de comércio, devem ser incentivadas.

\section{Listeria monocytogenes ANALYSIS IN REFRIGERATORS AND SINKS ON DOMESTIC KITCHENS FROM THE CITIES OF OURO, CAPINZAL E ZORTEA, SC - BRAZIL.}

ABSTRACT: Listeria monocytogenes is the listeriosis agent in humans, with a $30 \%$ mortality rate in risk groups. The elderly, immunodepressed people, newborns and fetuses are the main affected by the disease, which is characterized by sepsis and abortion in the case of fetuses. The ability to thrive in unfavorable conditions is due to their selfplasticity, triggered by exposure to extreme environment (cold, heat and acidity). Due to outbreaks of food-borne diseases prevalent in domestic conditions, the observation of the occurrence of $L$. monocytogenes in a domestic environment appropriated to their survival and proliferation is very important. The refrigerators and kitchen sinks of sixty households were evaluated in the cities of Capinzal, Ouro and Zortéa, SC, through the collection of surface swabs. Samples were taken from the compartment of vegetables, meat and rubber seal, and in the sinks samples were taken from the drain. The results showed the presence of $L$. monocytogenes in the refrigerators meat trays at three houses with the simultaneous occurrence of $L$. ivanovii in one of them. It is therefore the risk of contamination by L. monocytogenes in homes due to the possibility of the fall of waste on the food, usually already prepared, stored on lower shelves of home appliances.

Keywords: Listeria monocytogenes. Domestic contamination. Listeria ivanovii. 


\section{REFERÊNCIAS}

AZEVEDO, I. et al. Incidence of Listeria spp in domestic refreigerators in Portugal. Food Control, n. 16, p. 121-124, 2005.

BALDASSI, L. et al. Prevalência de Listeria monocytogenes em amostras de carne de frango obtidas em abatedouros do estado de São Paulo. Higiene Alimentar, São Paulo, v.19, n.130, p.81-84, abr. 2005.

BELL, C.; KYRIAKIDES, A. Listeria - una a práctica al microorganismo y su control en los alimentos. Zaragoza: Ed. Acribia, 1998. 173 p.

DUFFY, G. et al. The effect of aeration, initial inoculum and meat microflora on the growth kinetics of Listeria monocytogenes in selective enrichment broths. Food Microb., v. 11, p. 429-438, 1994.

DUFFY, G. et al. Behaviour of Listeria monocytogenes in the presence of Listeria innocua during storage of minced beef under vacuum or in air at $0^{\circ} \mathrm{C}$ and $10^{\circ} \mathrm{C}$. Food Microb., v. 17, p. 517-578, 2000.

EUZÉBY, J. P. Dictionnaire de Bactériologie Vétérinaire. Disponível em: <http://www. bacterio.cict.fr/html>. (2000). Acesso em: 22 ago. 2003

FORSYTHE, S. J, Microbiologia da Segurança Alimentar. 1 ed. Porto Alegre: Artmed, 2002. 169 p.

GUERRA, M. M, BERNARDO, F. A. Multiplicação e sobrevivência de Listeria monocytogenes sob condições desfavoráveis. Higiene Alimentar, São Paulo, v.20, n.140, p.46-52, abr. 2006.

INTERNATIONAL STANDART ORGANIZATION. ISO 11290-2:1998/Amd.1:2004 :

Microbiology of food and animal feeding stuffs - Horizontal method for the detection and enumeration of Listeria monocytogenes - Part 1: Detection method. Amendment 1: Modification of enumeration medium. Geneve: International Standart Organization, 2004. 20 p.

JACKSON, V. et al. The incidende of significant foodborne pathogens in domestic refrigerators. Food Control, n. 18, p. 346-351, 2007. 
JAY, J. M, Microbiológia de Alimentos. 6 ed. São Paulo: Editora Artmed. 2005. 316 p.

JEONG, D.K; FRANK, J.F. Growth of Listeria monocytogenes at $10^{\circ} \mathrm{C}$ in biofilms with microoganisms isolated from meat and dairy processing environments. Journ. Food Protection, n. 57, p. 576-586, 1994.

KESKININ, L.A; TODD, E.C. D; RYSER, E.T. Impact of bacterial stress and biofilmformin hability on transfer of surface-dried Listeria monocytogenes during slicing of delicatessen meats. Intern. Journ. Microb., n. 127, p. 298-304, 2008.

MENDES, S. D. C. Detecção de Listeria spp em frangos resfriado pelos métodos convencional em condições de anaerobiose e microaerofilia. 2000. 145 f. Dissertação (Mestrado em Ciência dos Alimentos) - Universidade Federal de Santa Catarina - UFSC, Florianópolis, 2000

OLIVEIRA, L. A. T. et al. Biofilme na indústria de alimentos. Higiene Alimentar, São Paulo, v.20, n.141, p.33-35, maio/jun. 2006.

PELISSER, M. R. Detecção de Listeria spp em frangos resfriado comercializado em Florianópolis - SC, através de método rápido Clearview e método convencional. 1998. 112 f. Dissertação (Mestrado em Ciência dos Alimentos) - Universidade Federal de Santa Catarina - UFSC, Florianópolis, 1998.

SERGELIDIS, D. et al. Temperature distribution and prevalence of Listeria spp in domestic, retail and industrial refrigerators in Greece. Intern. Journ. Microb., n. 34, p. 171-177, 1997.

SOFOS, J.N.; YOON, Y. Safer food using predictive modeling. Fleischwirtschaft International, n. 3, p. 16-21. 2006.

SOUZA, V.M.; et al. Survey of Listeria spp. in matched clinical, food and refrigerator samples at home level in Brazil. Food Control,v.19, n.10, p.1011-1013. 2008.

THÉVENOT, D. et al. Fate of Listeria monocytogenes in experimentally contaminated French sausages. Intern. Journ. Food Microb., n. 101, p. 189-200. 2005.

YOKOYAMA, E. et al. Production of bacteriocin-like-substance by Listeria innocua against Listeria monocytogenes. Intern. Journ. Microb., n. 40, p. 133-137, 1998. 


\section{SOBRE OS AUTORES}
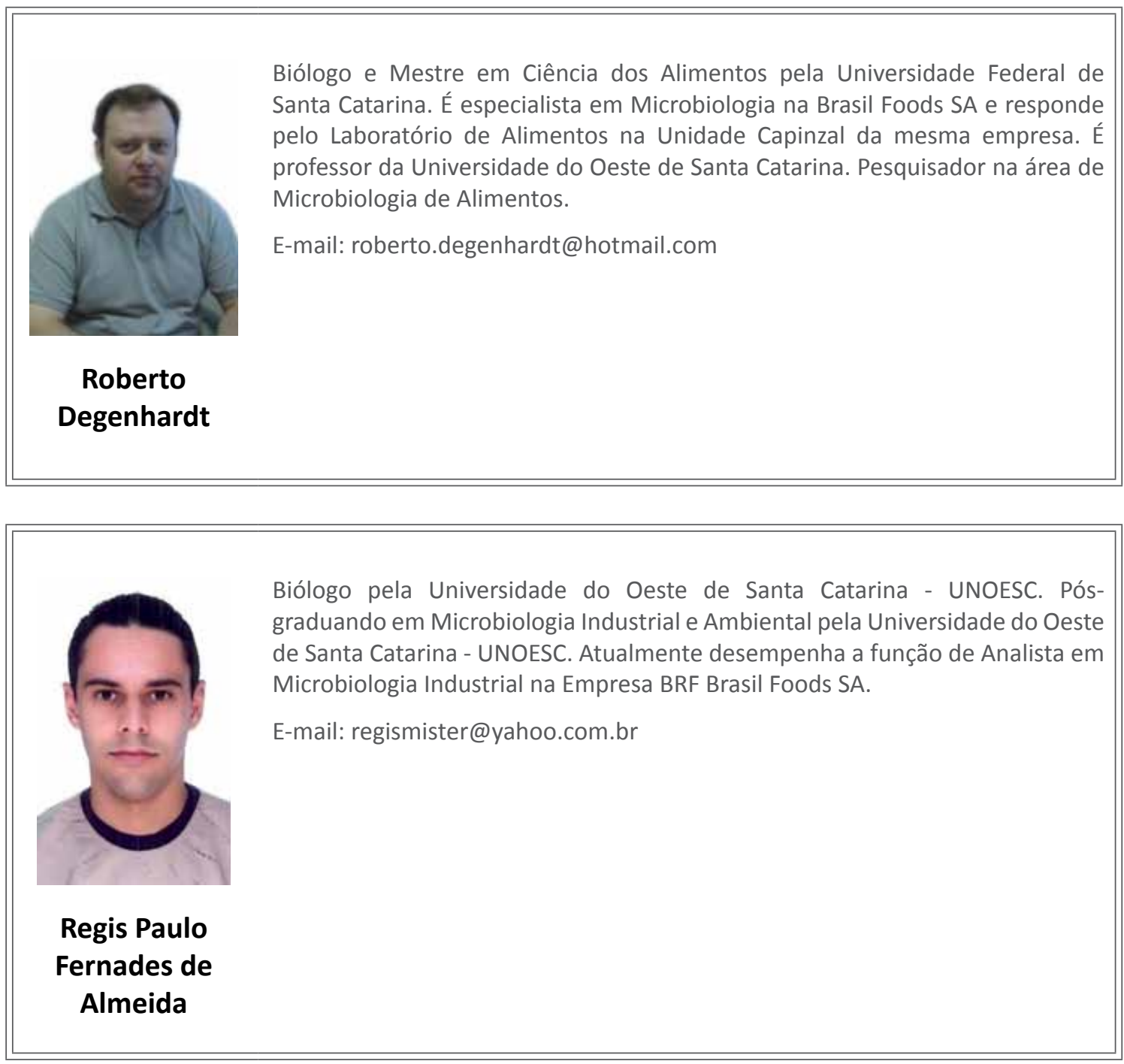